\title{
Group Psychotherapy With Fibromyalgia Patients: A Systematic Review
}

\author{
Esin TEMELOĞLU ŞEN®i, Ayla HOCAOĞLU®, Özlem SERTEL BERK@ \\ Department of Psychology, İstanbul University, İstanbul, Turkey
}

\begin{abstract}
Objectives: This review aims to investigate the factors that play a role on the efficacy of group psychotherapy (GP) interventions for fibromyalgia syndrome (FMS).

Materials and methods: We employed a search using keywords group psychotherapy and fibromyalgia in the databases of Scopus, Web of Sciences, CINAHL, BMJ, MEDLINE, ScienceDirect and EBSCOhost.

Results: A total of 30 original studies were identified. These studies, which aimed to improve primary outcomes (POs-pain and fibromyalgia impact) and/or secondary outcomes (SOs-psychosocial), indicated that 15 were conducted in a multidisciplinary (MT) fashion, and the rest were unidimensional as they employed only GPs. Cognitive behavior therapy, which modifies dysfunctional thoughts and accompanying behaviors, was the most utilized psychological intervention. Overall, MTs were only slightly superior to GPs; however, improvements in POs were more frequent than SOs in MTs, and the vice versa in GPs.

Conclusion: Although studies varied in various methodological characteristics, the content of the interventions in MTs should be designed to cover the biopsychosocial nature of FMS.

Keywords: Fibromyalgia; group psychotherapy; multidisciplinary approach; review.
\end{abstract}

According to the definition of American College of Rheumatology, fibromyalgia syndrome (FMS) is characterized by widespread musculoskeletal pain of the body lasting more than three months. ${ }^{1}$ It is the most common rheumatic syndrome and primarily females are affected. ${ }^{2,3}$ FMS is also a complicated syndrome as it includes not only pain in tender points around the body, but also many adverse psychological, social and economic outcomes. ${ }^{1}$ In addition to pain, FMS patients report anxiety, depression, ${ }^{4,5}$ fatigue, ${ }^{6}$ sleep disorder, ${ }^{7,8}$ sexual disorders, ${ }^{9}$ irritable bowel and leg syndrome ${ }^{10}$ or migraine. ${ }^{4}$ Cognitive and behavioral reactions to pain are critical because they can affect pain experience. Coping styles, self- efficacy, pain catastrophizing, patient satisfaction, pain acceptance and the (ab)use of medication are significant determinants of FMS symptomatology followed by negative consequences in the quality of life and daily functioning. ${ }^{11-13}$ Due to such a complex burden on economic, social and healthcare systems, practical and cost-effective interventions are needed. ${ }^{14-16}$

The major treatments for FMS are pharmacological interventions which mostly involve combined medicine including amitriptyline, tramadol, anticonvulsants, or serotoninnoradrenalin reuptake inhibitors. ${ }^{17}$ Although pharmacological strategies in treatment improve patient's symptoms, the effects remain limited and

Received: December 26, 2017 Accepted: May 18, 2018 Published online: July 31, 2019

Correspondence: Esin Temeloğlu Şen, PhD. İstanbul Üniversitesi Psikoloji Bölümü, 34452 Beyazıt, Fatih, İstanbul, Turkey. Tel: +90 542 - 5726477 e-mail: esin_tmlgl@yahoo.com 
last for a short time (almost six months after the beginning of drug use); in addition, patients stop using medication because of the side effects. ${ }^{17,18}$ Consequently, it is discussed that pure medical treatment may not be enough to deal with patients' multiple requests. Therefore, a biopsychosocial perspective in treatment is suggested. ${ }^{17,18}$ European League Against Rheumatism (EULAR) proposed multidisciplinary treatment approaches, which include physical exercises, and pharmacological and psychological treatments. ${ }^{17}$

Therefore, due to comorbid situations and psychosocial variables related to FMS, psychological treatment has an important place in multidisciplinary interventions. ${ }^{19,20}$ A great number of studies indicate that psychological treatment has beneficial effects on both primary outcomes (POs), which are pain intensity, fatigue, fibromyalgia impact and physical functioning, and secondary outcomes (SOs), which are mainly emotional stress (depressive and anxiety symptoms), coping, pain acceptance, and quality of life. ${ }^{19}$ POs are identified as measures of fibromyalgia impact and pain sensation whereas SOs are characterized by psychosocial variables that are reported to be associated with pain. ${ }^{20}$

Recently, group psychotherapy (GP) is the most common psychotherapy method for FMS patients with its outweighing advantages to individual psychotherapies. ${ }^{19}$ For example, it provides peer support, a sense of shared experience, and an opportunity to learn from and help others. Last but not least, it is more cost-effective. ${ }^{21,22}$ However, according to the literature, although FMS patients report various benefits from GP, some studies demonstrate that these benefits are insignificant. ${ }^{23-25}$ Moreover, most studies have not examined the effectiveness of their interventions on POs and SOs simultaneously. For those who have, some studies only state improvements in SOs, which, though, are not consistent across studies.

Because of these limitations or inconsistencies and a focus on only a specific group of variables, illuminating the factors that play a role in the effectiveness of GPs specific to FMS seems to be an important need. Therefore, in this review, we aimed to investigate the factors that play a role on the efficacy of GP interventions for FMS.

\section{MATERIALS AND METHODS}

In order to explore the conditions of effectiveness in GPs for FMS patients, a comprehensive bibliographic search of studies was employed using Istanbul University online library domain. Within this search, the social science and health science databases including Scopus, Web of Sciences, CINAHL, BMJ, MEDLINE, ScienceDirect, and EBSCOhost platforms were examined. While searching, the terms group psychotherapy and fibromyalgia were used as keywords without brackets in order to include all the manuscripts that may be of interest. This examination revealed that the first study which used GP for FMS patients was conducted in 1998. ${ }^{26,27}$

From this point on, in order to assess the effectiveness of GP interventions conducted with FMS patients, we focused only on studies that included GP as an intervention for FMS patients. Studies that did not use GP in the intervention were eliminated. On the other hand, since FMS symptoms are predominantly seen in adults, interventions involving adult patients were selected. ${ }^{2}$ In addition, studies which implemented semi-experimental or experimental designs in their interventions were in the scope of this review. In this process, databases were browsed by two reviewers and studies written in English or in Turkish were selected where the latter is the reviewers' native language. To summarize, the inclusion criteria were (i) empirical articles (experimental or quasi-experimental design) published in scientific journals, (ii) those written in English or Turkish language, (iii) those including only GP interventions, and (iv) those performed with adult samples (18 years and over) with FMS diagnosis. Exclusion criteria were (i) not including a GP intervention, (ii) including interventions with no pre- or post-assessments, (iii) being only a pilot study, (iv) those including individuals with diagnosis other than FMS (such as rheumatoid arthritis, chronic pain, osteoarthritis), and (v) those conducted with participants who are children or adolescents.

The search identified 1,710 articles. These articles were reviewed by inclusion and exclusion criteria. A total of 901 studies that were case reports or reviews were eliminated because of not being empirical studies. The remaining 
809 studies were reviewed by going over the abstract and the key words. Of these, 218 were duplicated, 453 did not include GP interventions, 10 were not conducted with adult patients, 50 did not involve FMS patients, and 18 were pilot studies. After excluding these articles with regard to inclusion/exclusion criteria, the remaining 60 articles were further analyzed. Among these final 60 articles, 21 were excluded because their full texts could not be reached and nine were also excluded as they included not only FMS patients but also other chronic pain patients. As a result, a total of 30 original articles were finally identified between 1998 and 2018. As the final total number of articles selected according to the inclusion and exclusion criteria stated above are limited in number, this review covers all these 30 articles within this time-span. The flowchart of the selection process described above is summarized in Figure 1.

\section{RESULTS}

Among the 30 articles analyzed in this systematic review, it was observed that in most of the studies, patients had been diagnosed according to FMS criteria which were indicated by Wolfe et al. ${ }^{28}$ The participants were mostly females where some studies included samples only with females. The sample size had a range of 7 to 168 . With respect to research design, 11 studies were observed to have no control groups. On the other hand, only three of the remaining 19 studies that used control groups were conducted using a randomized control trial (RCT) (Table 1). The number of the sessions changed between 6 and 36 .

In terms of the presence of follow-up sessions, the review yielded 21 studies using follow-up examinations. The selection of the time-span of the follow-ups varied among the studies with a range of one month to 12 months. The most frequently administered instruments to assess the effectiveness of the interventions were Visual Analog Scale, Fibromyalgia Impact Questionnaire (FIQ), the 36-Item Short Form Health Survey, and European Quality of Life-5 Dimension (Table 1). A few studies employed sensory measures such as algometric pressure, incremental step test, dolorimetry, cold pressure test, tender point counts, and total myalgia score.

Another variable investigated in this review was the drop-out rates. It was observed that reported rates varied among these 30 studies. For example, the study of Suman et al. ${ }^{29}$ reported no drop-out patients, while the studies

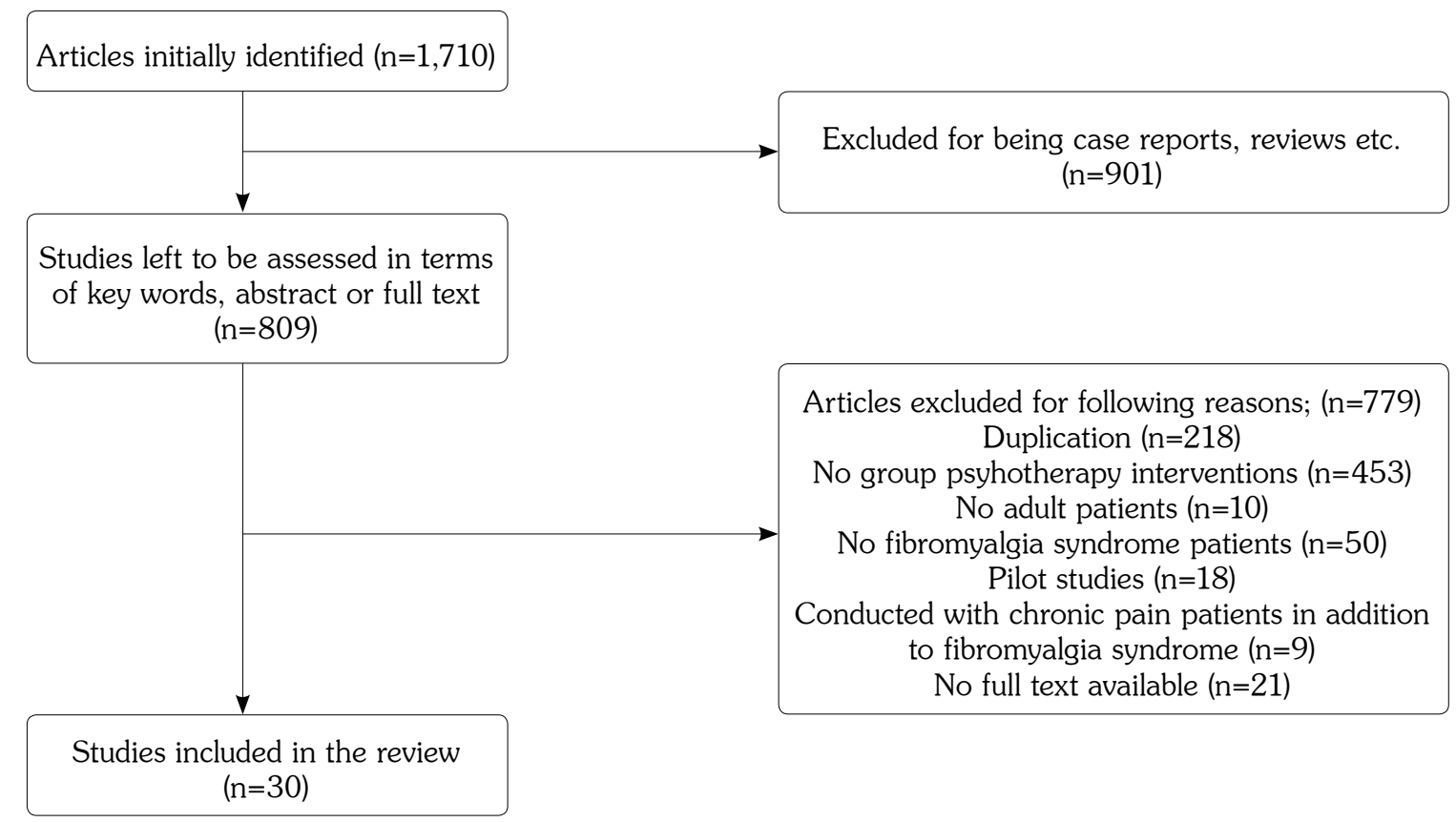

Figure 1. Flowchart of selection process of articles included in this review. 


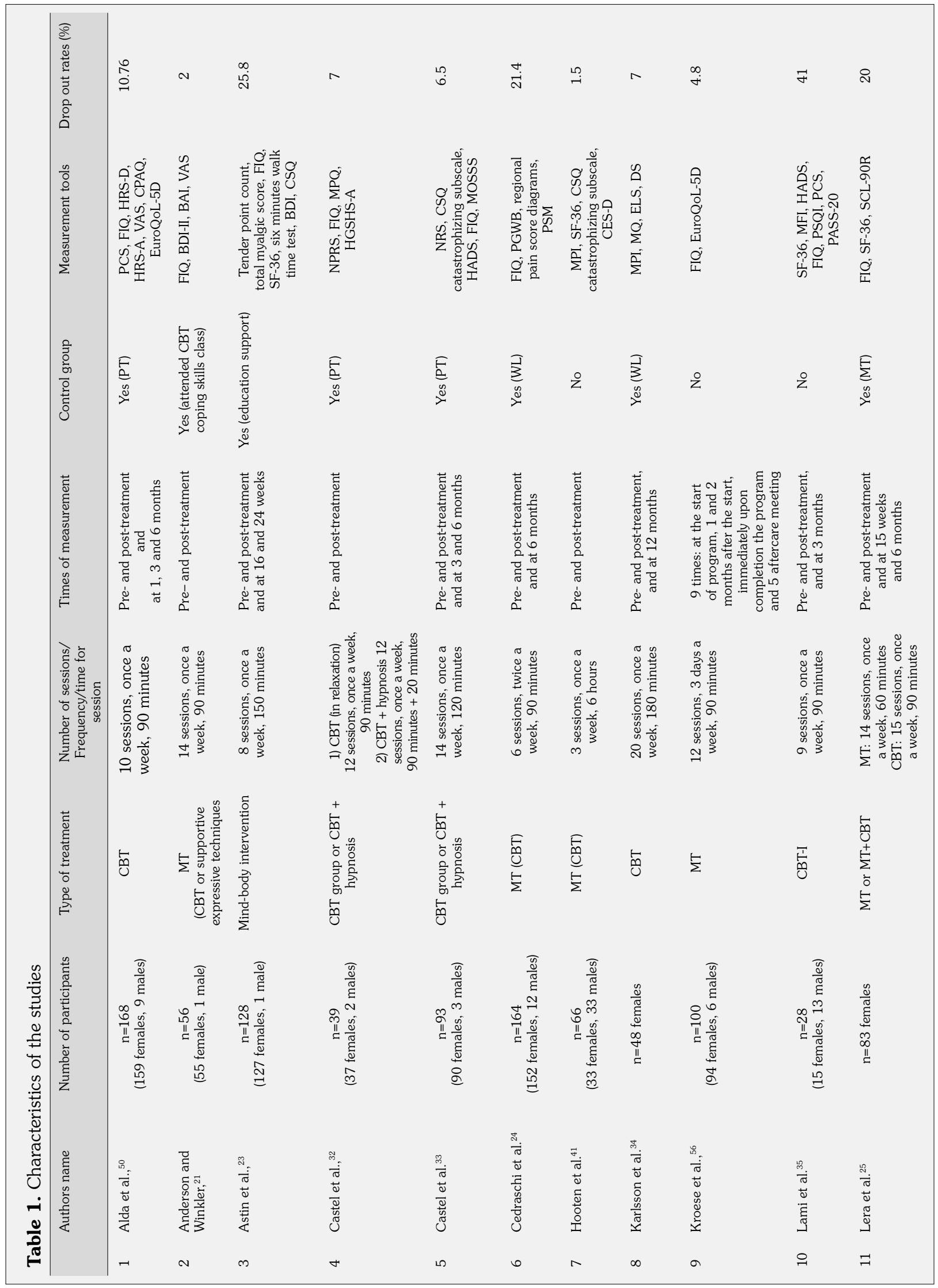




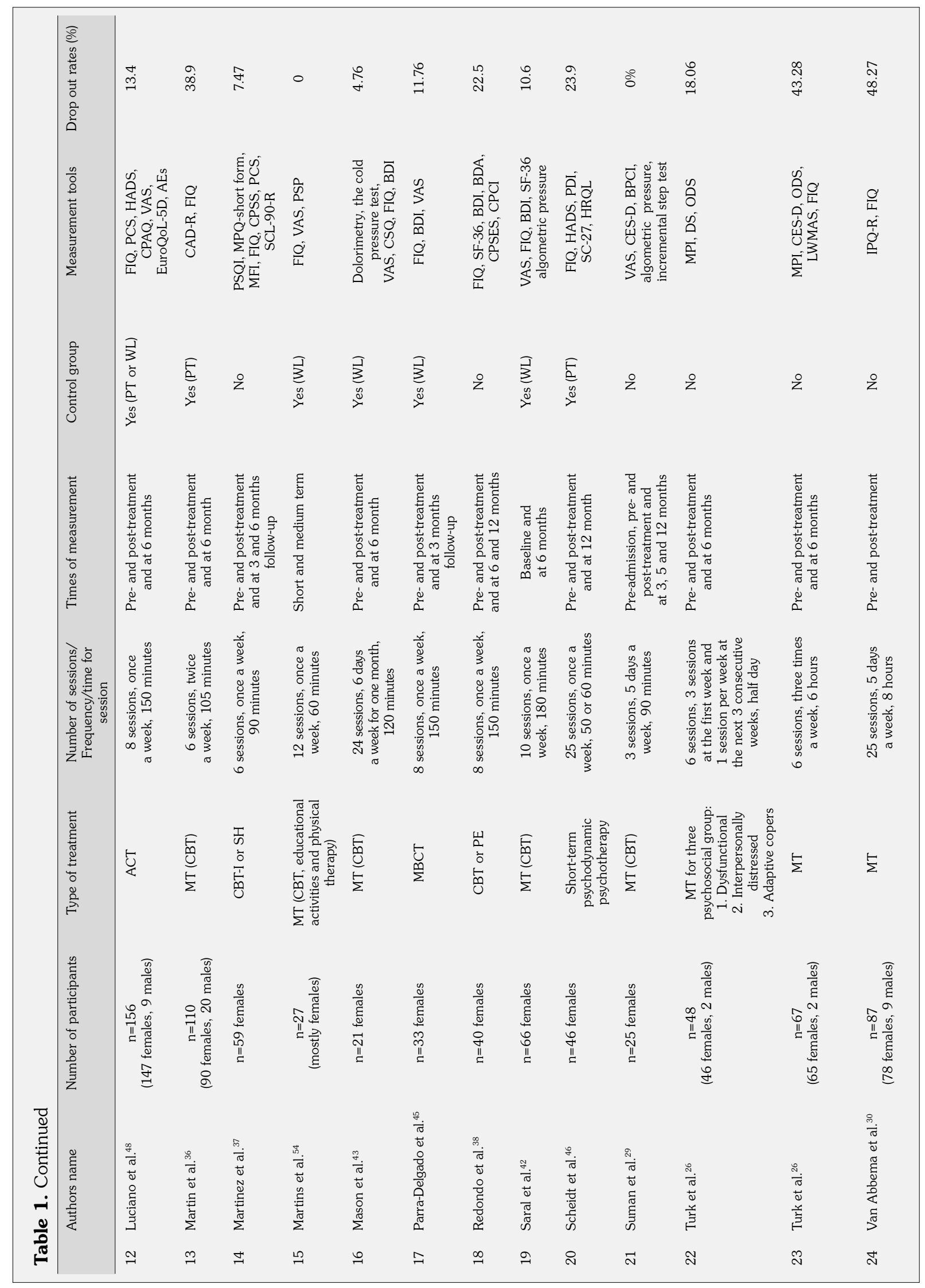




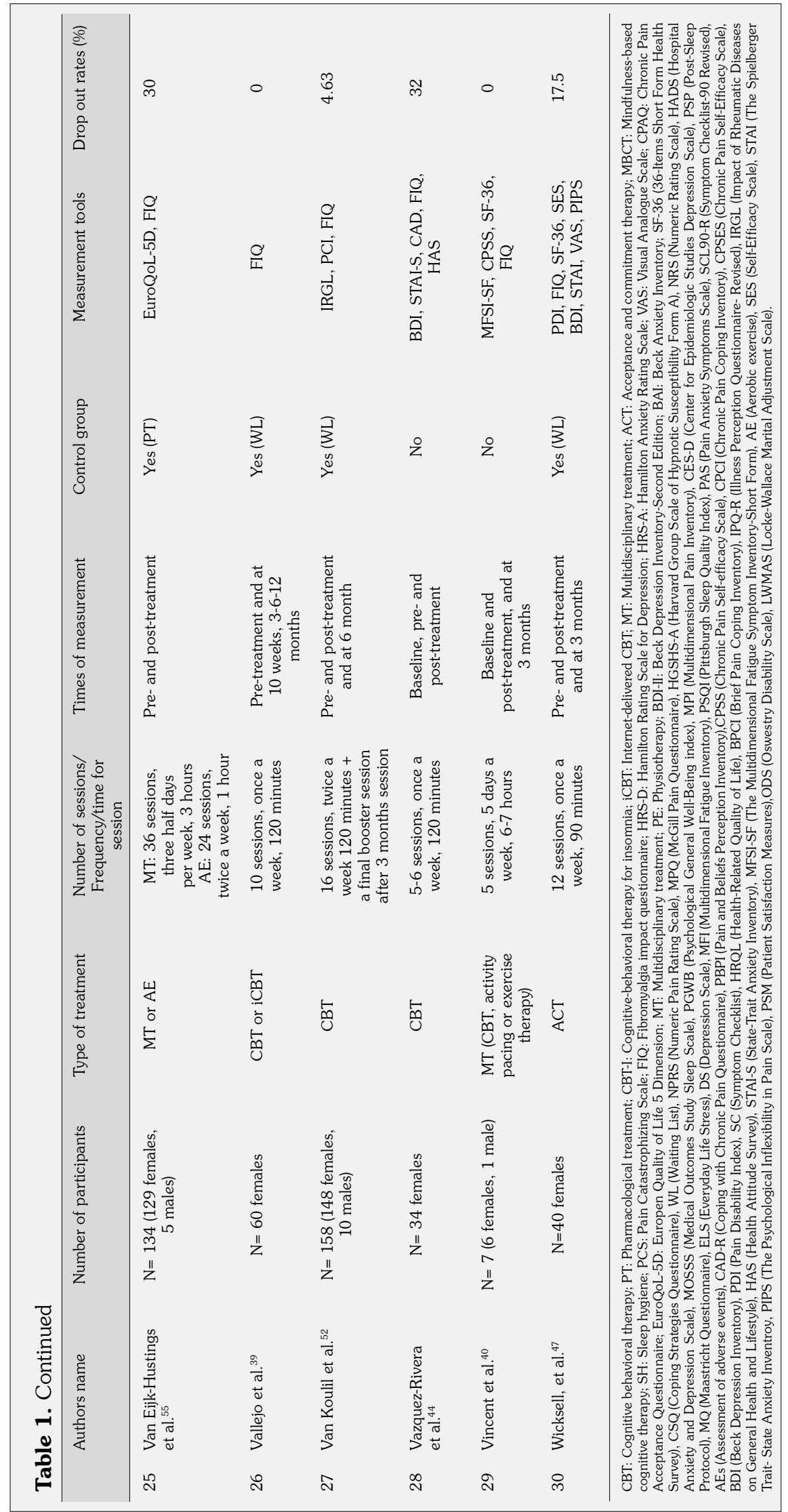




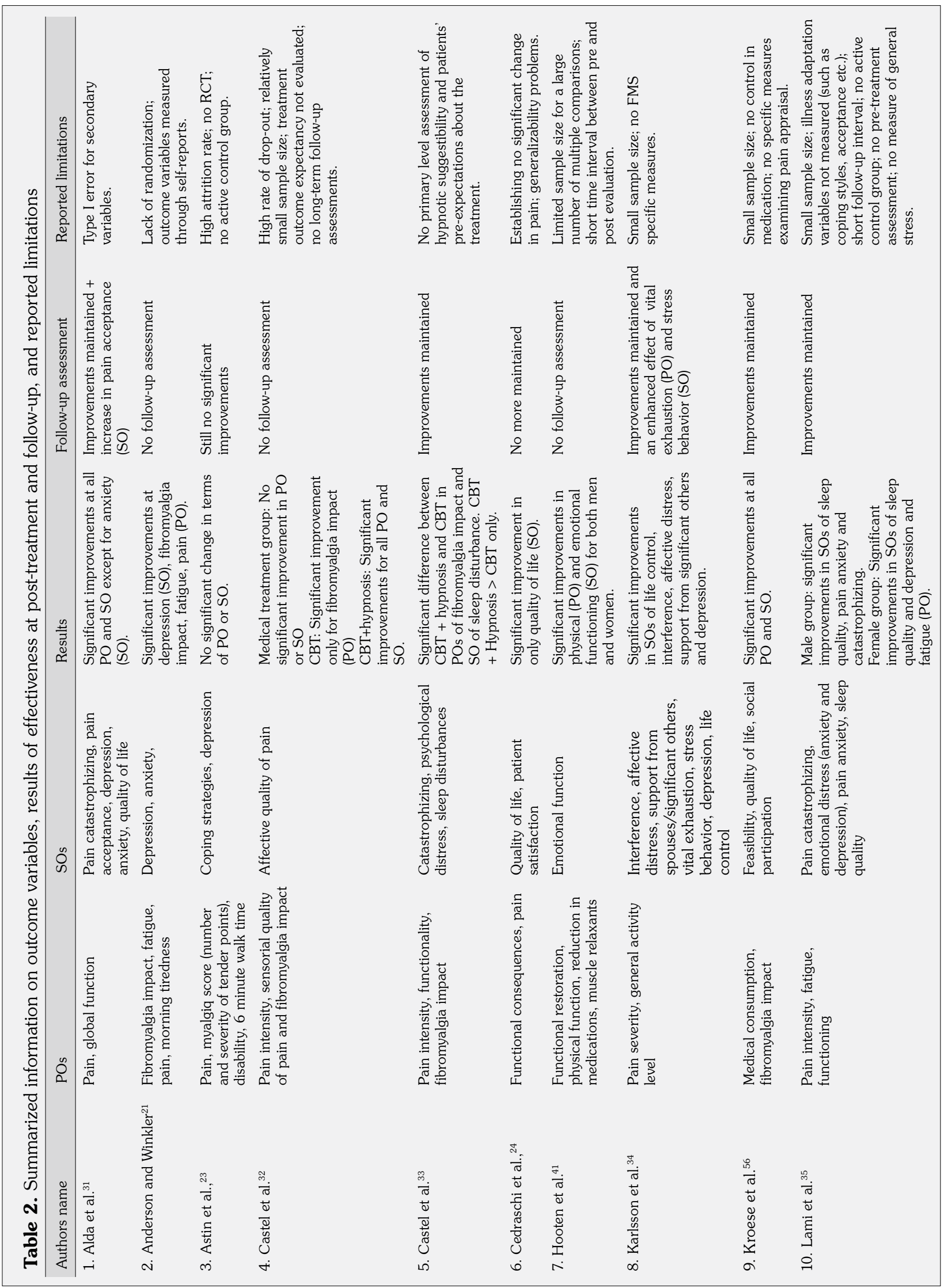




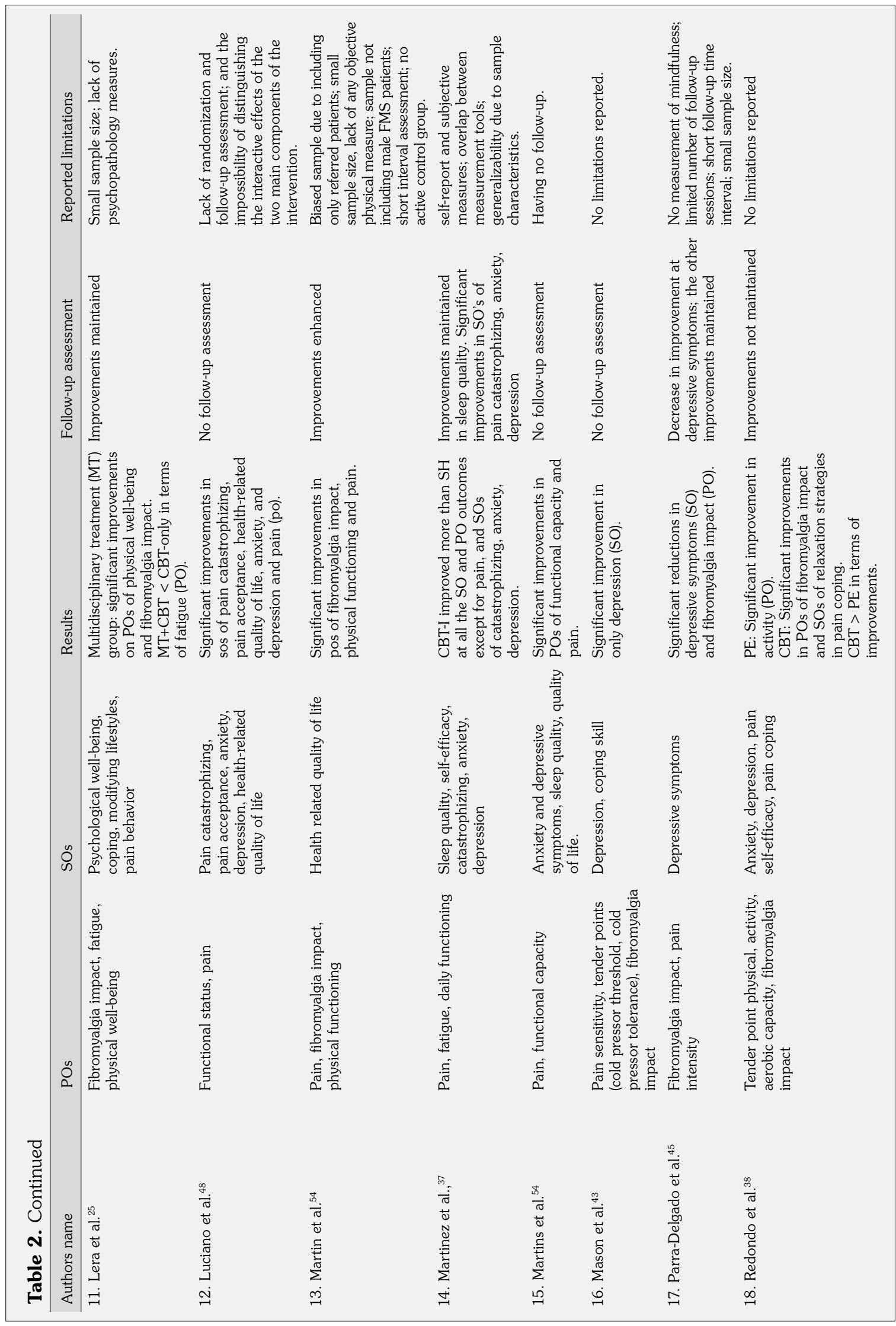




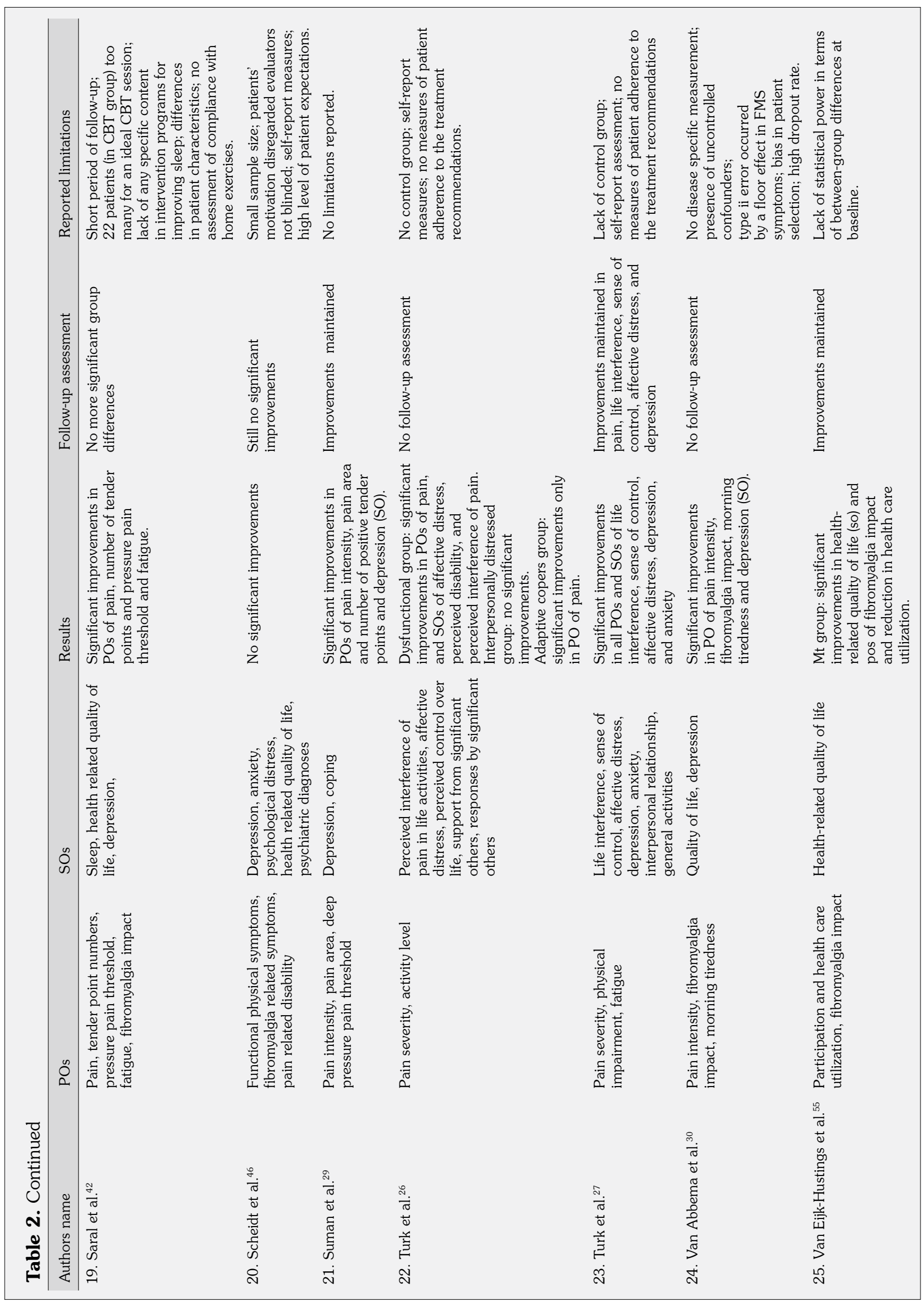




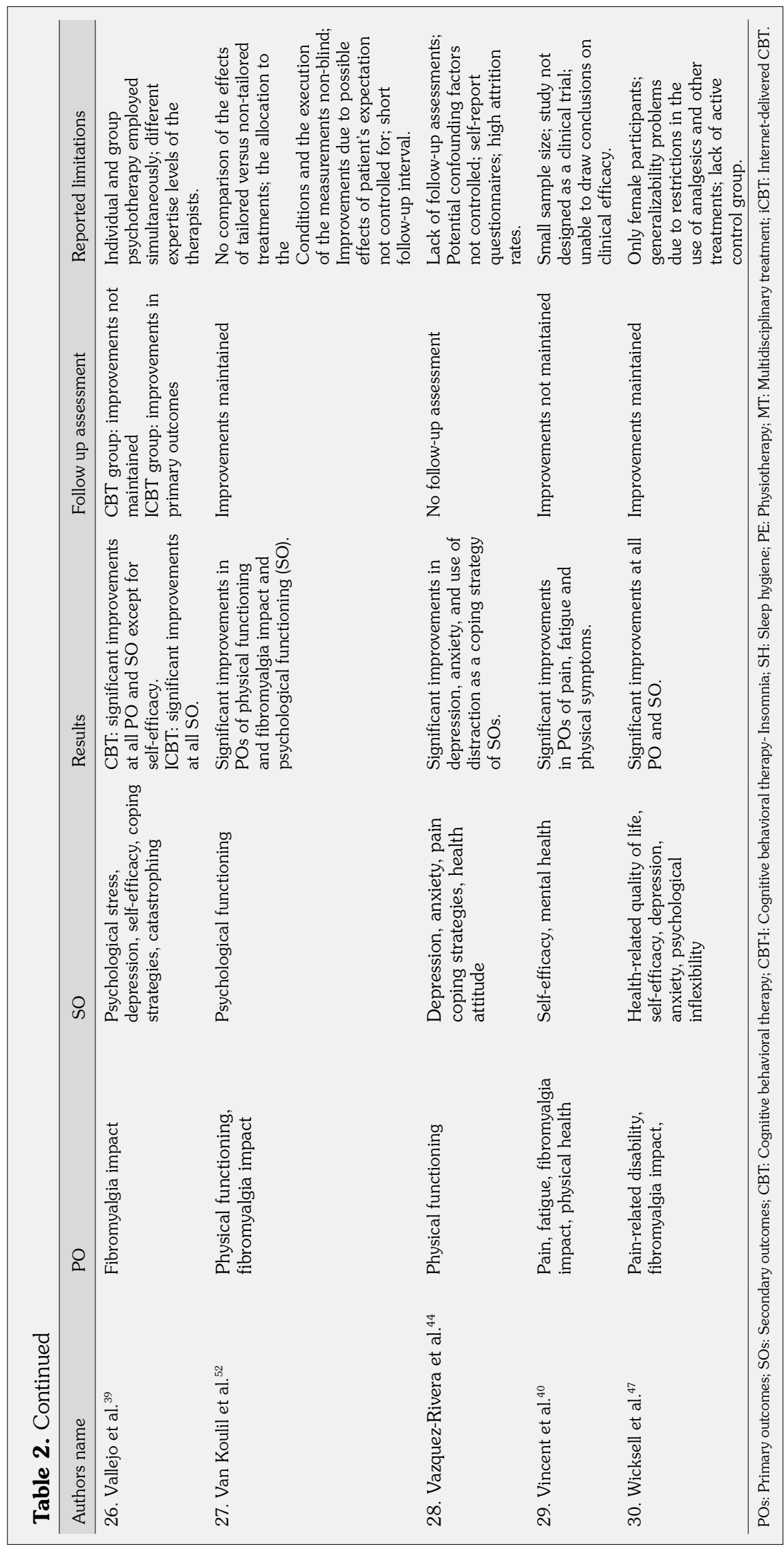


of Van Abbema et al., ${ }^{30}$ reported a drop-out rate which was almost 50\%, where the mean drop-out rate of these 30 studies was calculated to be $15.83 \%$ (standard deviation=14.21). Information including substantive characteristics (i.e. participants, type of treatment), methodological characteristics (i.e. design and instruments), external characteristics (i.e. publication bias, year of publication) are summarized in Table 1 and effectiveness of interventions are shown in Table 2.

As to the therapeutic interventions, Cognitive Behavior Therapy (CBT), which modifies dysfunctional thoughts and behaviors through cognitive techniques (i.e. cognitive restructuring) or behavioral activation (i.e. relaxation, increasing activity), ${ }^{29}$ was observed to be the main psychotherapy modality in 20 studies. With respect to these 20 studies, CBT was used as a single psychotherapeutic method in eight studies, CBT and hypnosis were combined in two studies, and CBT was joined with multidisciplinary programs in 10 (Table 1). The remaining 10 studies were based on different psychotherapeutic approaches aside from CBT; one being a mind-body intervention, two based on Acceptance and Commitment Therapy, one being a mindfulness-based cognitive therapy and one being short-term psychodynamic psychotherapy; the remaining five studies employed multidisciplinary interventions including physical exercise, drug management, and unidentified group psychotherapeutic techniques (Table 1). To summarize, these 30 studies indicated that 15 were conducted in a multidisciplinary fashion, and the rest employed unidimensional, in other words only GP interventions.

On the whole, these interventions aimed to improve POs including pain intensity, fatigue, fibromyalgia impact and/or SOs that consist of psychological factors such as depression, anxiety, quality of life, pain acceptance, and pain catastrophizing (Table 2). According to the results, it was observed that among the multidisciplinary interventions, eight studies revealed significant improvements in both POs and SOs, five studies in only primary, and two studies in only SOs. On the other hand, among the remaining 15 non-multidisciplinary/unidimensional treatments where only GP techniques were employed, nine showed improvements in both primary and secondary variables, two studies revealed changes only in primary and two studies only in secondary variables. However, there were two studies which reported no significant effects (Table 2).

These studies also reported some limitations such as having samples including mostly females, lack of randomization, high rates of drop-out, small sample size and generalizability problems, no long-term follow-up assessments, and lack of objective measures.

Despite these reported limitations, a further analysis was conducted for a more precise picture of the intervention effects as a function of outcome type (primary or secondary) and intervention type (multidisciplinary or unidimensional). For this purpose, percentage rates of improvements in $\mathrm{POs}, \mathrm{SOs}$ and overall improvements regardless of $\mathrm{POs}$ or SOs were calculated for multidisciplinary treatments (MTs; $\mathrm{n}=15$ ), and unidimensional/only GP treatments (U/GPs; $n=15$ ), respectively (Table 3).

These further results revealed that for MTs, among all outcome variables, 53\% were POs $(n=47)$, and $47 \%$ were SOs $(n=41)$; whereas for $\mathrm{U} / \mathrm{GPs}$, these rates were $38 \%(\mathrm{n}=37)$ and $62 \%(\mathrm{n}=58)$, respectively. Although the overall improvement rate calculated regardless of outcome type was only slightly better for MTs (59\%) when

Table 3. Rate and percentage of improvements as a function of intervention type and type of outcomes

\begin{tabular}{lccc}
\hline & $\begin{array}{c}\text { POs } \\
\text { (Rate of improvement/\%) }\end{array}$ & $\begin{array}{c}\text { SOs } \\
\text { (Rate of improvement/\%) }\end{array}$ & $\begin{array}{c}\text { POs+SOs } \\
\text { (Rate of improvement/\%) }\end{array}$ \\
\hline MTs $^{3}$ & $34: 47 / 72$ & $18: 41 / 44$ & $57: 88 / 59$ \\
GPs $^{4}$ & $16: 37 / 43$ & $38: 58 / 65$ & $54: 95 / 57$ \\
\hline $\begin{array}{l}\text { POs: Primary outcomes; SOs: Secondary outcomes; Rate of improvement: Number of outcomes reported to yield improvements divided by total number of } \\
\text { outcomes measured; \%: Percentage of improvement where rate of improvement is multiplied by 100; MTs: Multidisciplinary treatments; GPs: Unidimensional/ } \\
\text { only group psychotherapies. }\end{array}$
\end{tabular}


compared to U/GPs (57\%) (see PO+SO column in Table 3), these rates seemed to change in terms of type of outcome. That is, with respect to MTs, the improvement rates for $\mathrm{POs}$ and $\mathrm{SOs}$ were $72 \%$ and $44 \%$, respectively. On the other hand, these rates were $43 \%$ and $65 \%$, respectively, for U/GPs (Table 3).

\section{DISCUSSION}

In this systematic review, 30 studies were examined employing GP interventions for FMS patients, conducted between 1998 and 2018 . It was observed that studies have focused on different outcome variables associated with FMS and used various psychological approaches in this direction. Yet, these outcome variables could be grouped in two major categories of POs and $\mathrm{SOs}$ in line with EULAR recommendations. ${ }^{20}$ Furthermore, it also seemed useful to categorize various treatment modalities employed in these studies into U/GPs and MT approaches (employing medical/physical treatment modalities in addition to GP interventions).

With respect to this two-fold classification in terms of outcomes and treatment modalities, this review overall delineates that $\mathrm{CBT}$ was the most frequently utilized psychotherapeutic modality of GP interventions, be it a MT or a U/GP. ${ }^{21,24,25,29,31-44}$ On the other hand, other few interventions including different psychotherapeutic approaches (which are mindbody intervention, mindfulness based therapy, short-term psychodynamic psychotherapy, acceptance commitment therapy) aside from CBT were also utilized. ${ }^{23,45-48}$

However, the results of the studies revealed some inconsistencies. For some, there was either no difference between the groups or the intervention effects remained low or at a moderate level in terms of POs including pain intensity, fatigue, and physical functioning. This seemed to be the case for secondary variables like psychological stress (depressive and anxiety symptoms), sleep quality, self-efficacy, and pain coping strategies (Table 2).

The overall inconsistencies stated above might be a function of treatment type as exactly half of the studies employed U/GPs, and the rest
MTs, the latter proposed to be more functional. Indeed, it is known that FMS patients restrict their movements because of their pain intensity and feelings of weakness and demonstrate a decrease in their functionality. What is thus aimed in these multimodal interventions is to gradually increase muscular strength of patients with physical therapy. However, that patients believe exercise makes their pain worse is an obstacle that may result in exercise avoidance. Accordingly, there are studies in the literature which report that when patients start exercising, their pain level increases. ${ }^{49}$ At this point, interventions including physical exercise and CBT together become crucial and are suggested to stop the cycle of avoidance and fear of pain. ${ }^{50,51}$ In fact, there is one specific study in this review that used a multidisciplinary approach including CBT with a special focus on behavioral strategies (behavioral activation and exercise) to facilitate physical exercise, the results of which did show improved $\mathrm{POs}^{52}$ (Table 2).

Furthermore, unlike unidimensional interventions that use only psychotherapeutic modalities, MT approaches include physical exercises, pharmacological and psychological treatments. ${ }^{17,19}$ As a result, treatment modalities which employ only psychological or medical/ physical approaches independent of one another may miss the whole symptomatology of FMS patients where both primary and secondary variables interplay. The aim of $\mathrm{CBT}$ is primarily to identify and modify dysfunctional thoughts and secondly break the vicious circle between symptoms and dysfunctional performance by using behavioral interventions. ${ }^{53}$ Accordingly, including physical exercise and ongoing medical treatment in the multidisciplinary intervention is viewed as important to record improvements in associated primary and secondary symptoms. Therefore, if the treatment modality is multidisciplinary, this may result in changes in both primary and secondary variables. ${ }^{21,26,30,40,41,54}$ As expected, some of the MT studies in this review reported improvements not only in SOs such as depressive symptoms, quality of life, emotional functioning but also in POs including pain, fatigue, physical functioning and fibromyalgia impact. In addition to these reports, objective pain evaluations like pain area, tender points, and pressure pain threshold also improved significantly in some 
other studies. ${ }^{29,42}$ Besides, some of these studies showed improvements with regard to medical consumption and healthcare utilization. ${ }^{55,56}$

However, a closer look at the degree of improvements in terms of type of intervention and outcome variables made the way for one of the major findings of this review, which was not exactly in line with the above predictions (Table 3). First of all, MTs were only slightly more effective than U/GPs in terms of improvements, when the outcomes were not split into POs and SOs. Furthermore, MTs included in this review yielded a higher frequency of improvements in $\mathrm{POs}$ than SOs. There was an exactly opposite finding for U/GPs. The finding for U/GPs is not contrary to the expectations as summarized above. On the other hand, one possible explanation for the result concerning MTs can be the $\mathrm{PO} / \mathrm{SO}$ ratio. A detailed analysis manifested a $\mathrm{PO} / \mathrm{SO}$ ratio higher in MTs when compared to U/GPs (Table 3). This can be evaluated as a MT bias where MTs may primarily be designed to emphasize changes particularly in POs. Yet, this review also shows that PO frequency in MTs only slightly outweighed SOs, whereas this ratio was twice in favor of SOs in U/GPs. This suggests that although MTs have more or less met the standards, this seems more in quantity rather than quality. It may be the case that the quality (that is the content) of MTs are more likely to meet the anticipations of FMS patients who primarily consult with not secondary but primary symptoms, when compared to unidimensional CBT or psychological based GPs. However, the present review may not answer this possibility. Nevertheless, further interventions can contemplate on improving MTs in terms of content as well. $21,26,30,40-42,54-56$

In addition to the above findings, there are studies mentioned in this review which showed low or no treatment effect or insignificant group differences in terms of primary and/or secondary variables. $^{24,42,43}$ One should not disregard that all these may actually be related with five major methodological problems which are differences in number of sessions, employment of varying assessment tools, lack of (active) control group or RCTs, the absence and features of follow-up evaluations, and drop-out rates. Firstly, in terms of number of sessions, even though more intense and more frequent long-term interventions are suggested to enhance the effectiveness of the interventions, ${ }^{57}$ there is a gradual increase in the number of interventions employing brief CBT modules because of its cost-effectiveness. ${ }^{29,44}$ More research is needed comparing the shortand long-term therapy effects as a function of the number of sessions with RCTs.

Secondly, among the scales used in these studies, only FIQ evaluates the impact of FMS in terms of biopsychosocial perspective and this was the only scale that was developed specifically for FMS patients. ${ }^{24}$ However, FIQ was administered in only some of the studies. Also, another major problem in evaluating FMS symptoms is the lack of objective measures. Only a few studies used objective means such as tender point counts, morning tiredness, and cold pressures. ${ }^{23,24,29,42,43}$ It will be of advantage to employ objective measures where possible. As a result, the proof of the effectiveness of any intervention is limited to the extent of the method of measurement.

Thirdly, there are studies that lack control groups. There seems to be a need for more RCTs with "active control groups" which are implemented as another well-acknowledged intervention for illness conditions ${ }^{58}$ besides the use of waitlist controls. Fourth, with respect to follow-up evaluations, there are studies covered in this review that have not conducted follow-ups. However, Kroese et al. ${ }^{56}$ discussed that even one follow-up may not be enough. They suggested using "aftercare meetings" which are conducted in shorter time spans following the final session, and for several times. According to them, besides the aim of maintaining the improvements, these meetings could be a means to track changes in the improvements in a longitudinal fashion. Moreover, it is not only the presence or the frequency, but also the time interval of the follow-ups that may have made a difference. This is an issue on its own that is to be tested in RCTs.

Lastly, drop-out is also the most important obstacle against studies while assessing the effects of intervention. Therefore, in order to grasp the intervention effects, keeping patients within the interventions is crucial. However, the sample studies included in this review also varied as a function of drop-out rates. The literature indicates that the main reason of drop-out is heterogeneity 
of the samples. ${ }^{36,56,59}$ Therefore, this may suggest that the difference in the level of heterogeneity among the studies might also have had an effect on varying outcomes of effectiveness. As a result, tailored interventions planned so as to increase retention rates may be a suggestion. ${ }^{52}$

Besides these suggestions for further research, this review bears some limitations. The first limitation was the language barrier in reaching all the studies which are written in non-English. Moreover, the search could not cover some databases such as Cochrane Library, PsycINFO, ProQuest, or PubMed since Istanbul University library has no access to these. Another limitation was the lack of covering studies conducted only using medical/physical modalities. Therefore, the issues with respect to the potential superiority of multidisciplinary approaches should rather be reassessed in comparison to medically oriented unidimensional studies as well. This review also cannot lead to the conclusion that GPs are the primary and effective means of psychological interventions. Future reviews should consider the effectiveness of various other forms of psychological interventions in comparison to GPs in the similar two-fold fashion as this review primary versus secondary variables and multidisciplinary versus unidimensional modalities.

In conclusion, with respect to the results of this review, the major clinical suggestion may be to provide FMS patients a treatment setting where both medical/physical and psychological modalities are available simultaneously, so that the multidisciplinary quality can be satisfied. Another major suggestion may be to repeatedly evaluate improvements not only in one modality of symptoms but both at primary (i.e. exercise avoidance, pain intensity) and secondary (i.e. fear of exercise and fear of pain) levels with efficient instruments sufficient to cover the major goals of change, including objective measures, where possible. All of these may help multidisciplinary modalities in reaching the gold standard. ${ }^{60}$

\section{Declaration of conflicting interests}

The authors declared no conflicts of interest with respect to the authorship and/or publication of this article.

\section{Funding}

The authors received no financial support for the research and/or authorship of this article.

\section{REFERENCES}

1. Wolfe F, Clauw DJ, Fitzcharles MA, Goldenberg DL, Häuser W, Katz RL, et al. 2016 Revisions to the 2010/2011 fibromyalgia diagnostic criteria. Semin Arthritis Rheum 2016;46:319-29.

2. Lawrence RC, Felson DT, Helmick CG, Arnold LM, Choi H, Deyo RA, et al. Estimates of the prevalence of arthritis and other rheumatic conditions in the United States. Part II. Arthritis Rheum 2008;58:26-35.

3. Mas AJ, Carmona L, Valverde M, Ribas B. Prevalence and impact of fibromyalgia on function and quality of life in individuals from the general population: results from a nationwide study in Spain. Clin Exp Rheumatol 2008;26:519-26.

4. Turkyilmaz AK, Kurt EE, Karkucak M, Capkin E. Sociodemographic characteristics, clinical signs and quality of life in patients with fibromyalgia. Eurasian $\mathrm{J}$ Med 2012;44:88-93.

5. Thieme K, Turk DC, Flor H. Comorbid depression and anxiety in fibromyalgia syndrome: relationship to somatic and psychosocial variables. Psychosom Med 2004;66:837-44.

6. Iacob E, Donaldson G, Neikrug A, Nakamura Y, Okifuji A. Self report ecological momentary assessment in patients with fibromyalgia to examine temporal relationships between pain with mood, fatigue, and sleep. J Pain 2016;17:121.

7. Lineberger MD, Means JK, Edinger JD. Sleep disturbance and fibromyalgia. Sleep Med Clin 2007;2:31-9.

8. Stuifbergen AK, Phillips L, Carter P, Morrison J, Todd A. Subjective and objective sleep difficulties in women with fibromyalgia syndrome. J Am Acad Nurse Pract 2010;22:548-56.

9. Kalichman L. Massage therapy for fibromyalgia symptoms. Rheumatol Int 2010;30:1151-7.

10. Bennett RM, Friend R, Marcus D, Bernstein C, Han BK, Yachoui R, et al. Criteria for the diagnosis of fibromyalgia: validation of the modified 2010 preliminary American College of Rheumatology criteria and the development of alternative criteria. Arthritis Care Res (Hoboken) 2014;66:1364-73.

11. Alok R, Das SK, Agarwal GG, Salwahan L, Srivastava R. Relationship of severity of depression, anxiety and stress with severity of fibromyalgia. Clin Exp Rheumatol 2011;29:70-2

12. Newton-John TR, Mason C, Hunter M. The role of resilience in adjustment and coping with chronic pain. Rehabil Psychol 2014;59:360-5. 
13. Taylor SS, Davis MC, Yeung EW, Zautra AJ, Tennen HA. Relations between adaptive and maladaptive pain cognitions and within-day pain exacerbations in individuals with fibromyalgia. $\mathrm{J}$ Behav Med 2017;40:458-67.

14. Collado A, Gomez E, Coscolla R, Sunyol R, Solé E, Rivera J, et al. Work, family and social environment in patients with Fibromyalgia in Spain: an epidemiological study: EPIFFAC study. BMC Health Serv Res 2014;14:513.

15. Thompson JM, Luedtke CA, Oh TH, Shah ND, Long $\mathrm{KH}$, King $\mathrm{S}$, et al. Direct medical costs in patients with fibromyalgia: Cost of illness and impact of a brief multidisciplinary treatment program. Am J Phys Med Rehabil 2011;90:40-6.

16. Verhaak PF, Kerssens JJ, Dekker J, Sorbi MJ, Bensing JM. Prevalence of chronic benign pain disorder among adults: a review of the literature. Pain 1998;77:231-9.

17. Macfarlane GJ, Kronisch C, Dean LE, Atzeni F, Häuser W, Fluß E, et al. EULAR revised recommendations for the management of fibromyalgia. Ann Rheum Dis 2017;76:318-28.

18. Heymann RE, Paiva ES, Martinez JE, Helfenstein M $\mathrm{Jr}$, Rezende MC, Provenza JR, et al. New guidelines for the diagnosis of fibromyalgia. Rev Bras Reumatol Engl Ed 2017;57:467-76.

19. Lami MJ, Martínez MP, Sánchez AI. Systematic review of psychological treatment in fibromyalgia. Curr Pain Headache Rep 2013;17:345.

20. Carville SF, Arendt-Nielsen L, Bliddal H, Blotman F, Branco JC, Buskila D, et al. EULAR evidence-based recommendations for the management of fibromyalgia syndrome. Ann Rheum Dis 2008;67:536-41.

21. Anderson FJ, Winkler AE. An integrated model of group psychotherapy for patients with fibromyalgia. Int J Group Psychother 2007;57:451-74.

22. Sherman AC, Mosier J, Leszcz M, Burlingame GM, Ulman KH, Cleary T, et al. Group interventions for patients with cancer and HIV disease: Part I: Effects on psychosocial and functional outcomes at different phases of illness. Int $J$ Group Psychother 2004;54:29-82.

23. Astin JA, Berman BM, Bausell B, Lee WL, Hochberg $\mathrm{M}$, Forys KL. The efficacy of mindfulness meditation plus Qigong movement therapy in the treatment of fibromyalgia: a randomized controlled trial. J Rheumatol 2003;30:2257-62.

24. Cedraschi C, Desmeules J, Rapiti E, Baumgartner E, Cohen P, Finckh A, et al. Fibromyalgia: a randomised, controlled trial of a treatment programme based on self management. Ann Rheum Dis 2004;63:290-6.

25. Lera S, Gelman SM, López MJ, Abenoza M, Zorrilla JG, Castro-Fornieles $\mathrm{J}$, et al. Multidisciplinary treatment of fibromyalgia: does cognitive behavior therapy increase the response to treatment? J Psychosom Res 2009;67:433-41.
26. Turk DC, Okifuji A, Sinclair JD, Starz TW. Differential responses by psychosocial subgroups of fibromyalgia syndrome patients to an interdisciplinary treatment. Arthritis Care Res 1998;11:397-404.

27. Turk DC, Okifuji A, Sinclair JD, Starz TW. Interdisciplinary treatment for fibromyalgia syndrome: clinical and statistical significance. Arthritis Care Res 1998;11:186-95.

28. Wolfe F, Smythe HA, Yunus MB, Bennett RM, Bombardier C, Goldenberg DL, et al. The American College of Rheumatology 1990 Criteria for the Classification of Fibromyalgia. Report of the Multicenter Criteria Committee. Arthritis Rheum 1990;33:160-72.

29. Suman AL, Biagi B, Biasi G, Carli G, Gradi M, Prati $\mathrm{E}$, et al. One-year efficacy of a 3-week intensive multidisciplinary non-pharmacological treatment program for fibromyalgia patients. Clin Exp Rheumatol 2009;27:7-14.

30. Van Abbema R, Van Wilgen CP, Van Der Schans $\mathrm{CP}$, Van Ittersum MW. Patients with more severe symptoms benefit the most from an intensive multimodal programme in patients with fibromyalgia. Disabil Rehabil 2011;33:743-50.

31. Alda M, Luciano JV, Andrés E, Serrano-Blanco A, Rodero B, del Hoyo YL, et al. Effectiveness of cognitive behaviour therapy for the treatment of catastrophisation in patients with fibromyalgia: a randomised controlled trial. Arthritis Res Ther 2011;13:173.

32. Castel A, Salvat M, Sala J, Rull M. Cognitive-Behavioral group treatment with hypnosis: a randomized pilot trial in fibromyalgia. Contemp Hypn 2009;26:48-59.

33. Castel A, Cascón R, Padrol A, Sala J, Rull M. Multicomponent cognitive-behavioral group therapy with hypnosis for the treatment of fibromyalgia: longterm outcome. J Pain 2012;13:255-65.

34. Karlsson B, Burell G, Anderberg UM, Svärdsudd K. Cognitive behaviour therapy in women with fibromyalgia: A randomized clinical trial. Scand J Pain 2017;9:11-21.

35. Lami MJ, Martínez MP, Sánchez AI, Miró E, Diener FN, Prados G, et al.Gender Differences in Patients with Fibromyalgia Undergoing Cognitive-Behavioral Therapy for Insomnia: Preliminary Data. Pain Pract 2016;16:23-34.

36. Martín J, Torre F, Padierna A, Aguirre U, González $\mathrm{N}$, Matellanes $\mathrm{B}$, et al. Interdisciplinary treatment of patients with fibromyalgia: improvement of their healthrelated quality of life. Pain Pract 2014;14:721-31.

37. Martínez MP, Miró E, Sánchez AI, Díaz-Piedra C, Cáliz R, Vlaeyen JW, et al. Cognitive-behavioral therapy for insomnia and sleep hygiene in fibromyalgia: a randomized controlled trial. J Behav Med 2014;37:683-97.

38. Redondo JR, Justo CM, Moraleda FV, Velayos YG, Puche JJ, Zubero JR, et al. Long-term efficacy of therapy in patients with fibromyalgia: a physical 
exercise-based program and a cognitive-behavioral approach. Arthritis Rheum 2004;51:184-92.

39. Vallejo, MA, Ortega J, Rivera J, Comeche MI, VallejoSloker L. Internet versus face-to-face group cognitivebehavioral therapy for fibromyalgia: A randomized control trial. J Psychiatr Res 2015;68:106-13.

40. Vincent A, Whipple MO, Oh TH, Guderian JA, Barton DL, Luedtke CA. Early experience with a brief, multimodal, multidisciplinary treatment program for fibromyalgia. Pain Manag Nurs 2013;14:228-35.

41. Hooten WM, Townsend CO, Decker PA. Gender differences among patients with fibromyalgia undergoing multidisciplinary pain rehabilitation. Pain Med 2007;8:624-32.

42. Saral I, Sindel D, Esmaeilzadeh S, Sertel-Berk $\mathrm{HO}$, Oral A. The effects of long- and short-term interdisciplinary treatment approaches in women with fibromyalgia: a randomized controlled trial. Rheumatol Int 2016;36:1379-89.

43. Mason LW, Goolkasian P, McCain GA.Evaluation of multimodal treatment program for fibromyalgia. J Behav Med 1998;21:163-78.

44. Vázquez-Rivera S, González-Blanch C, RodríguezMoya L, Morón D, González-Vives S, Carrasco JL. Brief cognitive-behavioral therapy with fibromyalgia patients in routine care. Compr Psychiatry 2009;50:517-25.

45. Parra-Delgado M, Latorre-Postigo JM. Effectiveness of Mindfulness-Based Cognitive Therapy in the Treatment of Fibromyalgia: A Randomised Trial. Cognit Ther Res 2013;1:1-12.

46. Scheidt CE, Waller E, Endorf K, Schmidt S, König R, Zeeck A, et al. Is brief psychodynamic psychotherapy in primary fibromyalgia syndrome with concurrent depression an effective treatment? A randomized controlled trial. Gen Hosp Psychiatry 2013;35:160-7.

47. Wicksell RK, Kemani M, Jensen K, Kosek E, Kadetoff $\mathrm{D}$, Sorjonen $\mathrm{K}$, et al. Acceptance and commitment therapy for fibromyalgia: a randomized controlled trial. Eur J Pain 2013;17:599-611.

48. Luciano JV, Guallar JA, Aguado J, López-Del-Hoyo Y, Olivan B, Magallón R, et al. Effectiveness of group acceptance and commitment therapy for fibromyalgia: a 6-month randomized controlled trial (EFFIGACT study). Pain 2014;155:693-702.

49. Jones KD, Clark SR. Individualizing the exercise prescription for persons with fibromyalgia. Rheum Dis Clin North Am 2002;28:419-36.

50. Maquet D, Demoulin C, Croisier JL, Crielaard JM. Benefits of physical training in fibromyalgia and related syndromes. Ann Readapt Med Phys 2007;50:363-8

51. Bennett R, Nelson D.Cognitive behavioral therapy for fibromyalgia.Nat Clin Pract Rheumatol 2006;2:41624.

52. van Koulil S, van Lankveld W, Kraaimaat FW, van Helmond T, Vedder A, van Hoorn $\mathrm{H}$, et al. Tailored cognitive-behavioral therapy and exercise training for high-risk patients with fibromyalgia. Arthritis Care Res (Hoboken) 2010;62:1377-85.

53. Richards SC, Scott DL. Prescribed exercise in people with fibromyalgia: parallel group randomised controlled trial. BMJ 2002;325:185.

54. Martins MR, Gritti CC, dos Santos Junior R, de Araújo MC, Dias LC, Foss $\mathrm{MH}$, et al. Randomized controlled trial of a therapeutic intervention group in patients with fibromyalgia syndrome.Rev Bras Reumatol 2014;54:179-84.

55. van Eijk-Hustings $\mathrm{Y}$, Kroese $\mathrm{M}$, Tan F, Boonen A, Bessems-Beks M, Landewé $R$. Challenges in demonstrating the effectiveness of multidisciplinary treatment on quality of life, participation and health care utilisation in patients with fibromyalgia: a randomised controlled trial. Clin Rheumatol 2013;32:199-209.

56. Kroese M, Schulpen G, Bessems M, Nijhuis F, Severens J, Landewé R.The feasibility and efficacy of a multidisciplinary intervention with aftercare meetings for fibromyalgia. Clin Rheumatol 2009;28:923-9.

57. Carbonell-Baeza A, Aparicio VA, Sjöström M, Ruiz JR, Delgado-Fernández M. Pain and functional capacity in female fibromyalgia patients. Pain Med 2011;12:1667-75.

58. Temple R, Ellenberg SS. Placebo-controlled trials and active-control trials in the evaluation of new treatments. Part 1: ethical and scientific issues. Ann Intern Med 2000;133:455-63.

59. Goldenberg D, Burckhardt C, Crofford L. Management of fibromyalgia. J Am Med Assoc 2004;17:2388-95.

60. Gatchel RJ, Okifuji A.Evidence-based scientific data documenting the treatment and cost-effectiveness of comprehensive pain programs for chronic nonmalignant pain. J Pain 2006;7:779-93. 